\title{
Application of genotype sensitivity to selection between two exotic strains of chickens in humid tropical environment
}

\author{
Jesuyon, Oluwatosin. M. $A^{1}$ and Salako, Adebowale. $E^{2}$ \\ 1, 2 Department of Animal Science, University of Ibadan, Nigeria \\ 1 E-mail: dr.oluwatosinjesuyon@yahoo.com GSM No: +234-0806-4310337 \\ 2 E-mail: aesalak@yahoo.com GSM No: +234-0803-3563559
}

\begin{abstract}
Genotype sensitivity as a change in the relative performance of a genotype in the presence of two or more environments could be an important factor in the breeding of exotic birds in the tropics. Farm records covering 10 years (1999 - 2008) were employed to study the effect of seasons on genotype sensitivity and their usability for selection in the breeding of exotic Parent stock chickens of Bovan and ISA origins in South-West Nigeria. Cock weight, hen weight, Hen-day production, egg weight, fertility of eggs set, hatchability of eggs set and pullet day-old chicks hatched were examined. Sensitivity analysis was conducted using the regression procedures of Microsoft Excel, 2007. Results revealed a lack of significant difference between genotypes in sensitivity indices within seasons, in body weight, HDP and egg weight. Due to Interaction between genotypes and seasons, the genotype sensitivity values demonstrated lack of definite pattern with the output levels of FES and HES between genotypes. Genotype sensitivity in the presence of genotype - season interaction, could be reliable for making choices between chicken genotypes in the humid tropics, especially in early dry season.
\end{abstract}

Keywords: Bovan nera, choices, Isa brown, parameters, reproduction.

\section{INTRODUCTION}

Avian species are sensitive to the environment and will respond according to the magnitude of the effect of the environment on their physiological wellbeing. Some (Abdou et al., 1977) have studied sensitivity reactions in poultry but an attempt has not been made to measure the magnitude of sensitivity, so as to give measurable indices to quantify sensitivity due to environments on domestic poultry genotypes. To measure sensitivity, it is important to establish the presence of genotype - season $(G \times S)$ interaction. This can be defined as the change in the relative performance of a genotype, e.g. body weight at 8 weeks, when reared under two or more seasons (Bowman, 1974). In an environment with different seasons, each change in season brings about a specific and different effect on each genotype. An interaction therefore results when the change in season does not have the same effect on different genotypes (Falconer and Mackay, 1996), therefore bringing about different levels of reaction corresponding to the sensitivity of the genotypes to the changes experienced. Since a single genotype is a genetically uniform group, the variance observed on the genotype will entirely be due to seasonal differences among individuals within the genotype. The phenotypic value of an individual in a genotype then becomes: $P=G+(E+I$ G.E. $)$. Statistically, seasonal sensitivity of a genotype to an environment (e.g. season) will be the regression of the genotype's phenotypic value on the phenotypic mean value of all genotypes, from all the seasons, in the environment environmental values - (Falconer and Mackay, 1996).

$$
Y=a+b X
$$

Where $Y=$ genotype's response in season

$\mathrm{a}=$ intercept or genotypic constant for the season

$b=$ power or sensitivity coefficient for $a$ trait of the genotype

$X=$ Mean of all genotypes, from all seasons, in the environment (environmental values).

Khan et al., (2006) showed a classical case of seasonal sensitivity when they reported that the local chicken strains of Bangladesh recorded highest egg production of $52.78 \%$ in winter, followed by summer, spring and late autumn productions respectively. 
Therefore, seasonal sensitivity is a component of the genotype - environment ( $G \times E)$ interaction. Large differences in sensitivity among genotypes in various seasons may lead to a reversal of the order of merit (Falconer and Mackay, 1996) among the genotypes. Sensitivity indices could help us to understand responses of genotypes to different seasons in an environment and thus give comparative values which could assist to rank and discriminate between them during decision making process for choice strain to adopt for production. When an environment increases a character or trait, it is termed 'good' but when it decreases character, it is termed 'bad' (Falconer and Mackay, 1996). In this regard, the humid tropical region of Ibadan in South-West Nigeria may be classified as 'bad' because of its high temperature and high humidity, thus making it depressive and endemic in nature. They also concluded that in good environments, high sensitivity brings high performance but in bad environments low sensitivity brings about high performance. Therefore upward selection in this 'bad' region will pick individuals or genotype with low sensitivity. It is expected that a genotype that records lower sensitivity in production and reproduction traits in an environment will be a better strain. This study was undertaken to measure the magnitude and study the nature of seasonal sensitivity, therefore investigate its possible application as a tool for making production choice between two parent-stock genotypes namely Bovan Nera (BN) and ISA Brown (IB) under hot humid conditions. The tested hypothesis was that all genotypes will respond insignificantly to different seasons.

\section{MATERIALS AND METHODS}

The Environment: Ajanla farms are at Ibadan which is situated in the derived savannah area of Southwest Nigeria. The average annual weather data during the period of this study covering 10 years were rainfall $(111.27 \mathrm{~cm} /$ month), sunshine hours of $8.33 \mathrm{hrs} /$ day/month, wind speed of 2.61 $\mathrm{km} / \mathrm{hr} /$ month, mean monthly temperature of $26.63^{\circ} \mathrm{C}$ and mean monthly relative humidity of $74.51 \%$. Table 1 indicates the mean seasonal weather parameters of the farm location in Ibadan, South-west Nigeria from 1999 to 2008.

Table 1: Mean seasonal weather parameters of Ibadan, South-West Nigeria from 1999 to 2008

\begin{tabular}{|l|l|l|l|l|l|}
\hline Parameter & Early Wet & Late Wet & Early dry & Late dry & Mean \\
\hline Months & April - July & Aug - Oct & Nov - Jan & Feb - March & All-year \\
\hline Rainfall (cm) & $174.08 \pm 11.29^{\mathrm{a}}$ & $174.43 \pm 16.38^{\mathrm{a}}$ & $11.01 \pm 3.26^{\mathrm{b}}$ & $41.29 \pm 8.75^{\mathrm{b}}$ & $111.27 \pm 8.96$ \\
\hline Sunshine (hours) & $8.95 \pm 1.17^{\mathrm{a}}$ & $6.17 \pm 1.07^{\mathrm{b}}$ & $8.27 \pm 1.19^{\mathrm{ab}}$ & $10.41 \pm 1.69^{\mathrm{a}}$ & $8.33 \pm 0.63$ \\
\hline Wind speed (Km/hr) & $2.78 \pm 0.20^{\mathrm{b}}$ & $2.1 \pm 0.20 \mathrm{c}$ & $2.26 \pm 0.21^{\mathrm{bc}}$ & $3.57 \pm 0.26^{\mathrm{a}}$ & $2.61 \pm 0.11$ \\
\hline Temperature $\left({ }^{\mathrm{O}} \mathrm{C}\right)$ & $26.37 \pm 0.21^{\mathrm{c}}$ & $25.24 \pm 0.14^{\mathrm{a}}$ & $26.99 \pm 0.14^{\mathrm{b}}$ & $28.70 \pm 0.16^{\mathrm{a}}$ & $26.63 \pm 0.14$ \\
\hline Relative Humidity (\%) & $79.53 \pm 0.68^{\mathrm{a}}$ & $82.00 \pm 0.68^{\mathrm{a}}$ & $66.37 \pm 1.36^{\mathrm{b}}$ & $65.45 \pm 1.47^{\mathrm{b}}$ & $74.51 \pm 0.83$ \\
\hline Rainy days & $12^{\mathrm{b}}$ & $14^{\mathrm{a}}$ & $1^{\mathrm{d}}$ & $4^{\mathrm{c}}$ & 31 \\
\hline
\end{tabular}

Means across rows with different superscripts are significantly $(\mathrm{P}<0.05)$ different

Experimental Materials and data collection: Records on Bovan nera (BN) and Isa brown (IB) parent-stock chickens were obtained from Ajanla Farms, Ibadan Nigeria, using 24 batches of each hybrid covering 10 years (1999-2008). The data collected were on cock weight $(\mathrm{CW})$, hen weight $(\mathrm{HW})$, hen-day production (HDP), egg weight (EW), fertility of eggs set (FES), hatchability of eggs set (HES) and pullet day-old chicks (PDC) hatched.

Seasons: The data were partitioned according to recognized seasonal patterns namely early wet (EW, April - July); late wet (LW, August - October); early dry (ED, November - January) and late dry (LD, February - March) for the study.

Experimental design and Statistical Analyses: Experimental design was randomized complete block. Data were then subjected to descriptive statistics, ANOVA, t-test, Duncan Multiple range test and regression analysis $(p<0.05)$ of SAS (1999). Interaction was examined by factorial ANOVA (SAS, 1999) while sensitivity values were estimated by regression procedures (Microsoft Excel, 2007). The response model $Y=a+b X$ was used, where $Y=$ observed value, $a=$ constant, $b=$ the sensitivity index while $X=$ environmental value, it is the general 
effect of the environment on all genotypes. The sensitivity analyses were conducted in two stages, first within seasons for both strains - this estimates the effect of each season on both strains at a time, and then between seasons - this procedure estimates the effect of each season with respect to the entire environment on both strains and thus useful for broad level comparison within the environment.

\section{RESULTS}

Genotype by season interaction: Table 2 shows the mean body weight, productive and reproductive values of parameters on Bovan nera and Isa brown parent stock chickens in Ibadan. The specific effects of seasons were depicted by the various output levels of the parameters. The result of factorial ANOVA indicated that significant $(P<0.05)$ interaction existed between genotype and season in mean cock weight. Bovan nera cocks exhibited higher body weight: $2451.72 \mathrm{~g}$, in LD season; while Isa brown cock indicated higher weight: $2543.66 \mathrm{~g}$, in ED season.

Table 2: Mean body weight, productive and reproductive output in Bovan Nera and ISA Brown Parent stock chickens in Ibadan

\begin{tabular}{|c|c|c|c|c|c|c|}
\hline Parameter & Genotype & E-wet & L-wet & E-dry & L-dry & Mean \\
\hline \multirow{2}{*}{$\begin{array}{l}\text { Cock body } \\
\text { weight, gm }\end{array}$} & $\mathrm{BN}$ & 2176.83 & 2162.93 & 2115.09 & 2451.72 & 2214.14 \\
\hline & IB & 2221.87 & 2112.91 & 2543.66 & 2098.98 & 2226.63 \\
\hline \multirow{2}{*}{$\begin{array}{l}\text { Hen body } \\
\text { weight, gm }\end{array}$} & $\mathrm{BN}$ & $1671.02^{y}$ & $1677.74^{\mathrm{y}}$ & $1669.11^{y}$ & $1923.11^{\mathrm{ax}}$ & 1724.81 \\
\hline & IB & 1590.67 & 1596.93 & 1497.56 & $1514.67^{\mathrm{b}}$ & 1549.83 \\
\hline \multirow[t]{2}{*}{ HDP, \% } & $\mathrm{BN}$ & 60.77 & 65.57 & $63.23^{b}$ & 61.45 & 62.73 \\
\hline & IB & 66.74 & 69.38 & $72.92^{\mathrm{a}}$ & 67.34 & 69.08 \\
\hline \multirow[t]{2}{*}{ Egg weight, gm } & $\mathrm{BN}$ & $56.20^{b}$ & 56.68 & 56.66 & $54.71^{b}$ & 56.05 \\
\hline & IB & $59.99^{a}$ & 57.97 & 58.12 & $56.88^{\mathrm{a}}$ & 58.23 \\
\hline \multirow{2}{*}{$\begin{array}{l}\text { Fertility of eggs } \\
\text { set, \% }\end{array}$} & $\mathrm{BN}$ & $80.82^{a}$ & $86.23^{b}$ & 82.77 & 84.57 & 83.61 \\
\hline & $\mathrm{IB}$ & $88.87^{b}$ & $89.45^{\mathrm{a}}$ & 84.47 & 84.20 & 86.70 \\
\hline \multirow{2}{*}{$\begin{array}{l}\text { Hatchability of } \\
\text { eggs set, } \%\end{array}$} & $\mathrm{BN}$ & $69.08^{b}$ & 73.13 & 68.85 & 70.36 & 70.35 \\
\hline & IB & $73.59^{a}$ & 73.88 & 68.32 & 67.73 & 70.86 \\
\hline \multirow{2}{*}{$\begin{array}{l}\text { Pullet DOCs, } \\
\%\end{array}$} & $\mathrm{BN}$ & $32.58^{\mathrm{b}}$ & 34.56 & 32.46 & 33.02 & 33.10 \\
\hline & $\mathrm{IB}$ & $36.06^{a}$ & 35.74 & 33.25 & 32.44 & 34.36 \\
\hline
\end{tabular}

NOTE: HDP means Hen day Production, PDOC means Pullet day-old chicks

Within-season genotype sensitivity: Table 3 indicates genotype sensitivity indices of body weight, hen day production, egg weight, fertility of eggs-set, hatchability of eggs-set and pullet day-old chicks produced (PDC) within-season for Bovan nera and Isa hens. Analysis of within-season values revealed that sensitivity within seasons between genotypes were significantly $(P<0.05)$ different from each other. T-test showed no significant differences $(\mathrm{P}>$ 0.05 ) between genotypic values, in body weight and productive traits, but significant differences $(\mathrm{P}<$ 0.05 ) were observed between sensitivity values of $\mathrm{BN}$ and IB breeder hens in reproductive traits. In fertility, hatchability and PDC, the lowest sensitivities in $\mathrm{BN}$ and IB were $0.90,0.86,0.85$ and $0.54,0.62$, 0.63 while the highest sensitivity values were 1.46 , $1.38,1.37$ and $1.10,1.14,1.15$ respectively. These lowest values were observed in LD, EW, EW and LW, LW, LW while the highest values were recorded in LW, LW, LW and LD, EW, EW seasons for BN and IB respectively. It was also observed that a uni- directional relationship was demonstrated between HW sensitivity and FES sensitivity indices, except in LD season. In LW season, the sensitivities of the reproductive traits in $\mathrm{BN}$ hens were higher than that of her body weight and also higher than that of the reproductive traits in Isa brown hens.

Between-seasons genotype sensitivity: Table 4 shows the effect of each season on the sensitivity of body, productive and reproductive traits of Bovan nera and Isa brown breeder hens within the environment. No significant $(p>0.05)$ differences were observed between genotypes in body weight, hen-day production and egg weight sensitivity indices. However, significant differences $(P<0.05)$ were observed between genotypes in HES and pullet day-old chicks (PDC) sensitivity values in ED season. In reproductive traits, interaction was implicated between genotype and season in HES, but not in PDC. BN recorded higher sensitivity values only in LW while IB hens had the upper values in EW, ED and LD seasons respectively. The largest 
difference in sensitivity between both genotypes: 0.76 , was obtained in favour of IB hen which had the lower index between the two in ED season. In PDC hatched, sensitivity indices were higher in Isa brown hens in all four seasons thus eliminating any interaction between genotype and season. As above,
ED season produced the largest difference of 1.40 between Bovan nera and Isa brown genotypes in favour of the later. Between-seasons and betweengenotypes, an inverse relationship was observed between HW sensitivity and each of HDP, EW, FES, HES and PDC sensitivities.

Table 3: Within-season sensitivity of Bovan nera and Isa brown genotypes classified by traits

\begin{tabular}{|c|c|c|c|c|c|}
\hline Parameters & Genotype & E-Wet & L-Wet & E-Dry & L-Dry \\
\hline \multirow{2}{*}{$\begin{array}{l}\text { Cock body } \\
\text { Weight }\end{array}$} & Nera & 1.00 & 1.02 & 1.16 & 0.97 \\
\hline & ISA & 0.99 & 0.98 & 0.84 & 1.03 \\
\hline \multirow{2}{*}{$\begin{array}{l}\text { Hen body } \\
\text { Weight }\end{array}$} & Nera & 1.05 & 1.03 & 1.06 & 1.01 \\
\hline & ISA & 0.95 & 0.97 & 0.94 & 0.99 \\
\hline \multirow[t]{2}{*}{ HDP } & Nera & 0.99 & 1.03 & 1.02 & 0.98 \\
\hline & ISA & 1.01 & 0.97 & 0.98 & 1.02 \\
\hline \multirow{2}{*}{$\begin{array}{l}\text { Egg } \\
\text { Weight }\end{array}$} & Nera & 0.96 & 1.11 & 1.04 & 0.98 \\
\hline & ISA & 1.04 & 0.89 & 0.96 & 1.02 \\
\hline \multirow{2}{*}{$\begin{array}{l}\text { Fertility of } \\
\text { Egg-set }\end{array}$} & Nera & $1.40^{\mathrm{a}}$ & $1.46^{\mathrm{a}}$ & $1.36^{\mathrm{a}}$ & 0.90 \\
\hline & ISA & $0.60^{b}$ & $0.54^{b}$ & $0.64^{b}$ & 1.10 \\
\hline \multirow{2}{*}{$\begin{array}{l}\text { Hatchability } \\
\text { of Egg-set }\end{array}$} & Nera & $0.86^{\mathrm{b}}$ & $1.38^{\mathrm{a}}$ & 0.97 & 0.91 \\
\hline & ISA & $1.14^{\mathrm{a}}$ & $0.62^{\circ}$ & 1.03 & 1.09 \\
\hline \multirow{2}{*}{$\begin{array}{l}\text { Pullet } \\
\text { DOCs }\end{array}$} & Nera & $0.85^{\mathrm{b}}$ & $1.37^{\mathrm{a}}$ & 0.92 & 0.91 \\
\hline & ISA & $1.15^{\mathrm{a}}$ & $0.63^{\mathrm{b}}$ & 1.08 & 1.09 \\
\hline
\end{tabular}

Paired values in same cell with different superscripts are significantly $(P<0.05)$ different

Table 4: Between - seasons sensitivity of Bovan nera and Isa brown genotypes classified by Traits.

\begin{tabular}{|c|c|c|c|c|c|}
\hline Parameters & Genotype & $\begin{array}{l}\text { E- } \\
\text { Wet }\end{array}$ & $\begin{array}{l}\text { L- } \\
\text { Wet }\end{array}$ & E-Dry & L-Dry \\
\hline \multirow{2}{*}{$\begin{array}{l}\text { Cock body } \\
\text { Weight }\end{array}$} & Nera & 0.938 & 1.054 & 1.478 & 1.118 \\
\hline & ISA & 0.798 & 0.908 & 1.218 & 1.185 \\
\hline \multirow{2}{*}{$\begin{array}{l}\text { Hen body } \\
\text { Weight }\end{array}$} & Nera & 0.995 & 1.058 & 1.211 & 1.103 \\
\hline & ISA & 0.617 & 0.894 & 1.036 & 1.082 \\
\hline \multirow[t]{2}{*}{ HDP } & Nera & 0.980 & 1.006 & 0.986 & 1.026 \\
\hline & ISA & 0.975 & 1.037 & 0.994 & 0.992 \\
\hline \multirow{2}{*}{$\begin{array}{l}\text { Egg } \\
\text { Weight }\end{array}$} & Nera & 1.436 & 1.946 & 1.933 & 0.931 \\
\hline & ISA & 1.511 & 1.849 & 1.930 & 0.971 \\
\hline \multirow{2}{*}{$\begin{array}{l}\text { Fertility of } \\
\text { Egg-set }\end{array}$} & Nera & 2.629 & 3.285 & 2.627 & 1.665 \\
\hline & ISA & 2.371 & 2.714 & 2.634 & 1.242 \\
\hline \multirow{2}{*}{$\begin{array}{l}\text { Hatchability } \\
\text { of Egg-set }\end{array}$} & Nera & 1.083 & 1.314 & $0.839^{b}$ & 1.589 \\
\hline & ISA & 1.528 & 1.091 & $1.596^{\mathrm{a}}$ & 1.835 \\
\hline \multirow{2}{*}{$\begin{array}{l}\text { Pullet } \\
\text { DOCs }\end{array}$} & Nera & 1.028 & 0.906 & $0.156^{b}$ & 1.613 \\
\hline & ISA & 1.414 & 0.969 & $1.560^{\mathrm{a}}$ & 1.925 \\
\hline
\end{tabular}

Paired values in same cell with different superscripts are significantly $(P<0.05)$ different

\section{DISCUSSION}

Genotype by season interaction: The presence of interaction between genotypes and seasons resulted to a reversal of the order of ranking between $\mathrm{BN}$ and IB genotypes, between late dry and early dry seasons respectively in cock body weight. This result negated the preliminary analyses of Adebambo et al. (2006) in which they reported that the effect of interaction of breed with season was not significant in the same environment. The present study could have been found significant because we have used a 10-year data for the study.

Within-season sensitivity: The significant differences obtained between genotypic sensitivity indices in EW and LW seasons in reproductive traits implied that there were differences between the genotypes. This meant that a large gap existed between Bovan nera and Isa brown within-season, in FES and HES, and PDC production, in favour of IB which recorded the lower sensitivity values to the seasons; and therefore demonstrated higher genetic ability in reproduction as seen in Table 2 . The highly significant sensitivity results displayed in reproductive traits by $\mathrm{BN}$ hen in EW and LW seasons resulted in lower genetic 
potential for reproduction in BN compared with IB hens in those seasons.

The lack of significant differences between genotypes within seasons, in body weight and productive traits, may mean that the physiological response mechanism in both genotypes within seasons were similar. Both could be adjudged as well adjusted to seasons in those traits. Although BN hen had the higher body weight of the two genotypes, both could be considered as light-weight strains in view of the closeness of their sensitivities. Isa brown showed a more definite pattern in sensitivity values as body weights were lowest in ED season while other traits recorded their lowest sensitivities in LW season in which it recorded higher productive values of the two genotypes. The results on HDP sensitivity within-season in both genotypes contradicted the production results, meaning that seasons conferring higher sensitivity upon genotypes could not produce higher number of eggs. The results from this study suggests that under this environment poultry birds expend much physiological energy to combat the stress of the environment thereby leading to high sensitivity to the seasons, thus leaving less energy for production.

A ranking of both genotypes in order of magnitude of their sensitivity indices showed that BN hen was higher in all traits within season and within trait. IB hen was more productive than $\mathrm{BN}$ hen which had higher sensitivity to the seasons. Seasonal sensitivity studies in Fayoumi chicks (Abdou et al., 1977) reported that significant differences in hatchability was observed between lowly inbred lines in summer but not in highly inbred local chickens; but in fertility and hatchability, inbred lines were found to be more sensitive to seasonal variations than control chicks. But it has been noted earlier (Abdou and Moukh-tar, 1973) that it is possible to get reasonable hatchability in June (Egypt) if fertile eggs were set the next day of hatching. Highly inbred local chickens did not show any significant differences in sensitivity between seasons in their report. This was taken as an indication of better adaptability to the environment in local than in exotic chickens. Abdou et al., (1977) also noted a decrease in seasonal sensitivity as chicks advanced in age and this was attributed to genetic homeostasis in the local breeds, because alleles responsible for early growth were probably more sensitive to seasonal variations. The findings of this study suggested that highly sensitive genotypes in body weight, could be less productive. Bovan nera was genetically superior in hen weight while IB was superior in other traits studied.

Between-seasons sensitivity : Results of betweenseason sensitivity study revealed that in cocks, lower sensitivity resulted in higher body weight between genotypes in favour of IB while in hens higher sensitivity submitted higher body weight in favour of BN. This probably was an indication that there was a basic genotypic difference in their response mechanisms to seasons between the genotypes, of the male and the female, for growth and body weight development. In productive traits - HDP and egg weight - both lower and higher sensitivity values of Isa brown resulted in higher production levels above Bovan nera in all seasons. This was contrary to the pattern of results obtained in body weight between sexes of genotypes, and it also contradicts the interaction between sensitivity values observed between genotypes and seasons in both traits respectively.

Because of the influence of interaction between genotypes and seasons, the sensitivity values demonstrated lack of definite pattern with the output levels of FES and HES. BN genotype exhibited superiority in FES sensitivities except in ED season, while IB hens had higher sensitivity values in HES in all seasons except LW. In PDC production, there was no interaction in sensitivity indices but Isa brown eggs gave higher sensitivity indices and PDC than Bovan nera. This was similar to the behaviour of BN hen genotype for body weight, which demonstrated higher sensitivity and corresponding HW levels in all seasons. The significant difference obtained in the sensitivity values of $B N$ and IB in HES and PDC in $E D$ season indicated the difference in their genetic combination; and IB had the superior sensitivity and production indices in both traits.

Between-seasons results suggested that under tropical environment with different climatic seasons, $\mathrm{BN}$ and IB genotypes may respond variously at different and measurable sensitivity levels as they interact with seasons. The 'genotype and season' with the lowest index for HDP: LD; 0.992, did not translate to the highest HDP: ED; $72.92 \%$. Also the lowest sensitivity: LD; 0.931, in Egg weight did not translate to that with the highest Egg weight, EW; $59.99 \mathrm{gm}$. The same trend was observed in FES, HES and PDC hatched. Making a choice between genotypes in the face of genotype - season interaction could be cumbersome when using sensitivity indices as a tool to pick a better genotype, because of the inconsistency in sensitivity pattern 
with respect to production output of respective genotype. Selection for traits however may be based on sensitivity in conjunction with production output levels. By testing these two genotypic families of BN and IB under the four pre-defined seasons in the environment we can pick the better genotype by using the sensitivity in comparison with mean performance of each trait. Findings also suggested that selection between genotypes could be based on their sensitivity within-seasons. In hen, a decrease in body weight is desired, especially in heavy strains, to improve egg production and hatching traits. In the light of findings above, Isa brown was recommended for skilful farmers based on its better adaptability lower sensitivity and higher productivity, while Bovan nera was recommended to new-entrant farmers with less experience in poultry management based on its higher sensitivity and ruggedness in the environment.

Conclusions: An inverse relationship existed between hen weight, and all traits studied, within and between seasons, within and between genotypes. Between-seasons and between-genotypes, Isa cocks had lower sensitivity indices and higher body weight than Bovan cocks. Bovan hens had higher sensitivity with higher body weights. Despite the interaction of sensitivity values, Isa brown was better in HDP and Egg weight in all four seasons. From the findings of this study, the best choice could be made between strains in the presence of genotype-season interaction by using both genotype sensitivity and production output as basis for decision making. When making choices between chicken genotypes within seasons, sensitivity values could be a very useful selection tool. In early dry season, genotype sensitivity values could be utilized to pick the better strain to adopt for production in the presence of genotype-season interaction.

Funding: This work which was part of my Ph. D studies, was supported with funds provided from personal, private individuals and family sources.

\section{ACKNOWLEDGEMENT:}

I acknowledge the support and magnanimity of Dr. Olaitan. O. Olaofe, the General Manager of $\mathrm{CHI}$ (Ajanla Farms, Ibadan) Ltd. who gave the permission to my request for hatchery and production primary data for my Ph. D studies. This study spanned for over 5 years. I also acknowledge the pain-staking effort of my supervisor $\operatorname{Dr}$ A. E. Salako of the Breeding and Genetics Unit of the University of Ibadan, Nigeria; where I just concluded my studies.

\section{REFERENCES}

Abdou. F.H., Moukh-tar (1973). In: Abdou, F. H., Soltan, M., Abd-Ellatif, M., Ayoub, H (1977).

Sensitivity of inbred Fayoumi chicks to seasonal variations. Ann. Genet. Sel. Anim. 9 (4): 423 - 429.

Abdou, F.H., Soltan, M., Abd-Ellatif, M., Ayoub, H (1977). Sensitivity of inbred Fayoumi chicks to seasonal variations. Ann. Genet. Sel. Anim. 9 (4): 423 - 429.

Adebambo, A.O., Ozoje, M.O, Funmi Adebambo, Abiola, S.S (2006). Genetic variations in growth performance of Giriraja, Indian White Leghorn and improved indigenous chicken breeds in South West Nigeria. Nigerian J. Genet. 20: 7-16. Retrieved in August 2012 from

www.ajol.info/index.php/njg/article/viewfile/42247/9360

Bowman, J.C (1974). An introduction to animal breeding. The institute of Biology's studies in biology. No. 46. Edward Arnold Publishers, London. Reprinted 1979. Pages 52-55.

Falconer, D.S., Mackay, T.F.C (1996). Introduction to Quantitative genetics. Thomas Press (India) Ltd: Longman Group. $4^{\text {th }}$ edition. Pages 132-134, 321.

Horst Peter (1981). Constraints on the genetic improvement of Non-Ruminants in the Tropics. Animal Research and Development. 14: 120 - 135.

Khan, H., Miah, M.Y., Bhuiyan, Begum S., Hussein , Khanunv R (2006). Homestead poultry production in Sylhet region. International Journal of Poultry Science. 5 (11): 1092 - 1095. Retrieved in October 2008 from: http://www.ansijournals.com/ijps/2006/1092-1095.pdf.

Microsoft Excel computer software. 2007. Microsoft Corporation, USA.

Statistical Analytical Systems (SAS/STAT) Computer software. 1999. SAS Institute Incorporated, N C, USA. 